\title{
Smoking and the risk of acute coronary syndrome in young women treated in an emergency department
}

\author{
Alberto Dominguez-Rodriguez ${ }^{1,2,3^{*}}$, Eduardo Arroyo-Ucar ${ }^{1}$, Pedro Abreu-Gonzalez ${ }^{3,4}$, \\ Guillermo Burillo-Putze ${ }^{2,5}$ \\ ${ }^{1}$ Department of Cardiology, Hospital Universitario de Canarias, Tenerife, Spain \\ ${ }^{2}$ Facultad de Ciencias de la Salud, Universidad Europea de Canarias, Tenerife, Spain \\ ${ }^{3}$ Instituto Universitario de Tecnologías Biomédicas, Tenerife, Spain \\ ${ }^{4}$ Department of Physiology, Universidad de La Laguna, Tenerife, Spain \\ ${ }^{5}$ Department of Emergency Medicine, Hospital Universitario de Canarias, Tenerife, Spain \\ Email: ${ }^{*}$ adrvdg@hotmail.com
}

Received 15 May 2013; revised 20 June 2013; accepted 28 June 2013

Copyright (C) 2013 Alberto Dominguez-Rodriguez et al. This is an open access article distributed under the Creative Commons Attribution License, which permits unrestricted use, distribution, and reproduction in any medium, provided the original work is properly cited.

\begin{abstract}
The aim of this study is to compare the clinical characteristics of young women ( $<40$ years) with older ( $\geq 40$ years) admitted to the hospital emergency department with the diagnosis of acute coronary syndrome (ACS), and identify which cardiovascular risk factors are predictors to suffer an ACS in the group of young women. We included women consecutively admitted in a tertiary hospital with a diagnosis of ACS. A total of 118 women with a diagnosis of ACS were included. Young women were more likely to smok and had a higher proportion of coronary artery disease of one vessel. The multivariable logistic regression analysis showed that smoking was the only variable associated independently with the presence of ACS in young women (OR: 6.451, 95\% CI: 1.479 to 28.571, $p=0.01$ ). The findings of this study indicate that smoking is an independent predictor of ACS in women less than 40 years.
\end{abstract}

Keywords: Women; Smoke; Acute Coronary Syndrome; Emergency Department; Risk Factors

\section{INTRODUCTION}

In the western world, cardiovascular disease is the leading cause of death in women. Numerous previous studies have drawn attention to the worst hospital prognosis of women experiencing an acute coronary syndrome (ACS). Epidemiological studies have identified risk factors such as high blood pressure (HT), diabetes mellitus (DM),

\footnotetext{
Corresponding author.
}

smoking and physical inactivity as responsible, in large part, for ischemic heart disease in women [1]. However, probably due to the low incidence of ACS in young women, there are any published studies concerning this specific population [2]. The aim of this study is to compare the clinical characteristics of young women $(<40$ years), compared to with older ( $\geq 40$ years) admitted to the hospital emergency department with the diagnosis of ACS, and identify which factors are predictors to suffer an ACS in this group of patients.

\section{METHOD}

\subsection{Study Population}

Prospective cohort study with hospitalary follow-up, which evaluated all patients attended to the emergency department of a tertiary care hospital with a diagnosis of ACS. The population was divided into two groups, depending on their age: group A that included young women $(<40$ years), and group B formed by older women ( $\geq 40$ years). The diagnosis of ACS was established according to the criteria published in the literature [3]. ACS with ST-elevation was defined by the presence of compatible symptoms, persistent ( $>20 \mathrm{~min}$ ) ST-segment elevation $\geq 1 \mathrm{~mm}$ in at least 2 contiguous leads or the presence of left bundle branch block presumed to be a new occurrence, and elevated cardiac troponin-I $\geq 0.5 \mathrm{ng} / \mathrm{ml}$ (cut-off point $\geq 0.5 \mathrm{ng} / \mathrm{ml}$ for the diagnosis of AMI; immunological reagents of the Orthoclinical Diagnostics Vitros 5100 system, United States). ACS without ST-elevation was defined by the presence of compatible symptoms, cardiac troponin- $\mathrm{I} \geq 0.5 \mathrm{ng} / \mathrm{ml}$ and/or dynamic ST-segment changes $(\geq 1 \mathrm{~mm}$ decrease in 
the ST-segment or non-persistent elevation in at least 2 contiguous leads) [3].

Both groups were analysed cardiovascular risk factors (DM, HT, dyslipidemia, smoking and physical inactivity), time of onset of symptoms, pre-hospital care, hospital arrival form, analytical parameters, hospitalary anti-ischemic treatment and degree of coronary artery disease. Diagnostic coronary angiography was performed using 4 - 7 French Judkins catheters through femoral or radial approaches [4]. The study was approved by the Ethics Committee for Clinical Research of the institution, and all patients gave written informed consent.

\subsection{Statistical Analysis}

Qualitative variables were assessed using the $\chi 2$ test and Fisher's test, when it was necessary. Quantitative variables were compared using the $t$-test of Student. A multivariate analysis using binary logistic regression model was performed, being the dependent variable "group" and as independent variables, the ones that were statistically significant in the univariate analysis and those that could have clinical implications and/or could be etiologically possible. All P values were calculated by assuming the bilaterally and were considered significant when their value was less than 0.05 . Statistical analysis was performed using SPSS 15.0.

\section{RESULTS}

The baseline characteristics of the study population are summarized in Table 1. One hundred eighteen women were studied sequentially. Group A consisted of 18 women $<40$ years versus group B with a total of 100 women $\geq 40$ years. $61.1 \%$ of women $<40$ years were admitted with the diagnosis of ST-elevation ACS. On the other hand, $73 \%$ of women $\geq 40$ years were admitted with a diagnosis of ACS without ST elevation. Regarding the degree of coronary artery disease, in Group A predominated 1 vessel disease (61.1\%) and in Group B 3 vessel disease (34\%). Between both groups there were no statistically significant differences in the time of onset of symptoms to arrival to emergency department, pre-hospitalary emergency assistance, hospital arrival form, antiischemic drug therapy and revascularization treatment. None of the patients admitted with ACS were treated with oral contraceptives or hormone replacement therapy. Regarding cardiovascular risk factors, women in group A had lower proportions of diabetes and HT compared to group B. Smoking was more common between women in group A, as well as higher numbers of leukocytes and lower HDL cholesterol. The younger women smoked one more pack per day and the duration of smoking was of $15 \pm 3$ years. The multivariable logistic regression analysis (Table 2) showed that smoking was the only
Table 1. Baseline characteristics of the population study.

\begin{tabular}{|c|c|c|c|}
\hline & $\begin{array}{c}\text { Group A } \\
\text { (women }<40 \\
\text { years) } \\
\mathrm{N}=18\end{array}$ & $\begin{array}{c}\text { Group B } \\
\text { (women } \geq 40 \\
\text { years) } \\
\mathrm{N}=100 \\
\end{array}$ & $P$ values \\
\hline \multicolumn{4}{|l|}{ ACS-n (\%) } \\
\hline With ST elevation & $11(61.1)$ & $27(27)$ & \multirow[t]{2}{*}{0.004} \\
\hline Without ST elevation & $7(38.9)$ & $73(73)$ & \\
\hline Hipertension & $4(22.2)$ & $81(81)$ & $<0.001$ \\
\hline Diabetes mellitus & $4(22.2)$ & $60(60)$ & 0.003 \\
\hline Hypercholesterolemia & $8(44.4)$ & $66(66)$ & 0.08 \\
\hline Smoker & $8(44.4)$ & $6(6)$ & $<0.0001$ \\
\hline Sedentary & $7(38.9)$ & $47(47)$ & 0.52 \\
\hline $\begin{array}{l}\text { Time of onset of symptoms } \\
\text { to arrival in the emergency }\end{array}$ & $212.4 \pm 66.30$ & $223.8 \pm 72$ & 0.53 \\
\hline \multicolumn{4}{|l|}{ Form of arrival at hospital } \\
\hline Ambulance & $13(72.2)$ & $64(64)$ & \multirow[t]{2}{*}{0.74} \\
\hline Own & $5(27.7)$ & $36(36)$ & \\
\hline $\begin{array}{l}\text { Assistance pre-hospital } \\
\text { emergency }\end{array}$ & $12(67)$ & $60(60)$ & 0.44 \\
\hline \multicolumn{4}{|l|}{ CAD } \\
\hline $\begin{array}{l}\text { Without obstructive } \\
\text { lesions }\end{array}$ & $1(5.6)$ & $6(6)$ & \multirow{4}{*}{0.04} \\
\hline One vessel & $11(61.1)$ & $28(28)$ & \\
\hline Two vessel & $4(22.2)$ & $32(32)$ & \\
\hline Three vessel & $2(11.1)$ & $34(34)$ & \\
\hline PCI & $12(66.7)$ & $61(61)$ & 0.64 \\
\hline \multicolumn{4}{|l|}{ Pharmacologic treatment } \\
\hline ASA & $18(100)$ & $100(100)$ & 1 \\
\hline Clopidogrel & $18(100)$ & $100(100)$ & 1 \\
\hline Statins & $18(100)$ & $100(100)$ & 1 \\
\hline$\beta$-blockers & $15(83.3)$ & $90(90)$ & 0.76 \\
\hline Nitrates & $6(33.3)$ & $40(40)$ & 0.89 \\
\hline ACEI & $10(55.5)$ & $62(62)$ & 0.55 \\
\hline Ivabradine & $13(72.2)$ & $67(67)$ & 0.96 \\
\hline Leucocytes $\left(10^{9} / 1\right)$ & $9.5 \pm 2.3$ & $7.8 \pm 2.9$ & 0.023 \\
\hline Hemoglobin (g/dl) & $12.3 \pm 1.7$ & $11.8 \pm 1.7$ & 0.288 \\
\hline LDL-cholesterol (mg/dl) & $111.3 \pm 50.1$ & $94.3 \pm 41.5$ & 0.126 \\
\hline HDL-cholesterol (mg/dl) & $33.8 \pm 9.8$ & $39.7 \pm 10.5$ & 0.028 \\
\hline Creatinine (mg/dl) & $0.68 \pm 0.36$ & $0.89 \pm 0.56$ & 0.138 \\
\hline
\end{tabular}

Values are expressed as $\mathrm{n}(\%)$ or media $\pm \mathrm{SD}$. ACS: Acute coronary syndrome; ACEI: Angiotensin-converting enzyme inhibitors; ASA: Acetylsalicylic acid; CAD: Coronary artery disease; PCI: Percutaneous coronary intervention. 
Table 2. Results of logistic regression analysis using as dependent variable "group A versus B".

\begin{tabular}{cccc}
\hline Variables & OR & CI 95\% & P values \\
\hline Hipertension & 1.923 & $1.410-5.102$ & 0.20 \\
Diabetes mellitus & 1.960 & $1.275-4.901$ & 0.15 \\
Smoker & 6.45 & $1.479-28.571$ & 0.01 \\
CAD & 1.007 & $0.631-1.563$ & 0.97 \\
\hline
\end{tabular}

OR: odds ratio; CI: Confidence Interval; CAD: Coronary artery disease.

variable independently associated with the presence of ACS in young women $<40$ years.

\section{DISCUSSION}

We observed two important findings: 1) the low incidence of ACS in young women $(15.2 \%)$, which is consistent with previous literature [2]; and 2) in our study, smoking is an independent predictor of ACS in women less than 40 years. Several studies have previously shown that women who suffer ACS present an unfavourable cardiovascular risk profile. In published series, the age average at admission is greater than 70 years, the prevalence of risk factors such as HT or DM is greater, and coronary revascularization rates are lower than those observed in the male population [5]. Therefore, the American Heart Association, in collaboration with other scientific societies, has developed specific guidelines on cardiovascular prevention in women [6]. But there are still no publications that focus on the population of young women who suffer ACS and its relation to cardiovascular risk factors.

In our study, women $\geq 40$ years have more often cardiovascular risk factors (HT, diabetes and dyslipidemia) in contrast to younger women, where we found a greater proportion of smokers and low HDL. These high rates of smoking among young women have a clear social behaviour [6]. Moreover, the multivariate analysis showed that smoking is the only independent predictor of ACS in young women. Our obtained data are similar to MONICA study [7], sponsored by WHO, which investigated the risk factors for cardiovascular disease in 120,000 individuals aged 35 to 64 , from 21 countries, having suffered an ACS. In young male and female subjects, the risk of stroke in smokers was five times bigger compared to nonsmokers [8].

It seems clear about the great influence of smoking on this subgroup of patients, a priori low risk of cardiovascular events population. The underlying pathophysiological causes that make this population especially vulnerable remain unknown. There are many articles in the literature that demonstrate the high risk for having a coronary event in women that smoke $[7,8]$. Evidence- based measures need to be implemented to assist women to quit smoking (or to not start tobacco use). Effective tobacco control, such as full implementation of the WHO's Framework Convention on Tobacco Control, would be such a method. National and international organizations such as the International Network of Women against Tobacco and the WHO's Tobacco Free Initiative are important reference organisations to promote more effective tobacco cessation in women [9]. Although more men than women smoke than women, those women under 40 years who do smoke have a greater risk of coronary heart disease, and therefore it is imperative that the physicians should try to threat "aggressively" active smoking in this population, and have it significantly presented in their clinical history and diagnostic strategies [9].

Our study has limitations that should be considered. Our study is single-center study; therefore, the results cannot be extrapolated to other hospitals, where we may find different sociodemographic and health conditions. Furthermore, the sample size may be another limiting factor; however, we are able to show differences between the study groups, after adjusting for potential confounding variables. Finally, extra-hospitalary follow up of the patients is not performed, thus it is not possible to determine morbidity and mortality aspects.

In conclusion, the findings of this study show that smoking is a strong predictor of ACS in women under 40 who attend to the emergency department of a tertiary hospital. Physicians should try to threat "aggressively" active smoking in this population and have it significantly presented in their clinical history and diagnostic strategies $[2,10,11]$.

\section{REFERENCES}

[1] Held, C., Iqbal, R., Lear, S.A., et al. (2012) Physical activity levels, ownership of goods promoting sedentary behaviour and risk of myocardial infarction: Results of the INTERHEART study. European Heart Journal, 33, 452-466. doi:10.1093/eurheartj/ehr432

[2] López, B., Sánchez, M., Bragulat, E., et al. (2011) Validation of a triage flowchart to rule out acute coronary syndrome. Emergency Medicine Journal, 28, 841-846. doi:10.1136/emj.2010.096602

[3] Hamm, C.W., Bassand, J.P., Agewall, S., et al. (2011) ESC guidelines for the management of acute coronary syndromes in patients presenting without persistent STsegment elevation: The task force for the management of acute coronary syndromes (ACS) in patients presenting without persistent ST-segment elevation of the European Society of Cardiology (ESC). European Heart Journal, 32, 2999-3054. doi:10.1093/eurheartj/ehr236

[4] Naidu, S.S., Rao, S.V., Blankenship, J., et al. (2012) Clinical expert consensus statement on best practices in 
the cardiac catheterization laboratory: Society for cardiovascular angiography and interventions. Catheterization and Cardiovascular Interventions, 80, 456-464. doi:10.1002/ccd.24311

[5] Jneid, H., Fonarow, G.C., Cannon, C.P., et al. (2008) Sex differences in medical care and early death after acute myocardial infarction. Circulation, 118, 2803-2810. doi:10.1161/CIRCULATIONAHA.108.789800

[6] Mosca, L., Benjamin, E.J., Berra, K., et al. (2011) Effectiveness-based guidelines for the prevention of cardiovascular disease in women-2011 update: A guideline from the American Heart Association. Journal of the American College of Cardiology, 57, 1404-1423. doi:10.1016/j.jacc.2011.02.005

[7] Molarius, A., Parsons, R.W., Dobson, A.J., et al. (2001) Trends in cigarette smoking in 36 populations from the early 1980s to the mid-1990s: Findings from the WHO MONICA Project. American Journal of Public Health, 91, 206-212. doi:10.2105/AJPH.91.2.206

[8] Huxley, R.R., Yatsuya, H., Lutsey, P.L., Woodward, M.,
Alonso, A. and Folsom, A.R. (2012) Impact of age at smoking initiation, dosage, and time since quitting on cardiovascular disease in African Americans and whites: The atherosclerosis risk in communities study. American Journal of Epidemiology, 175, 816-826. doi:10.1093/aje/kwr391

[9] Howe, M., Leidal, A., Montgomery, D. and Jackson, E. (2011) Role of cigarette smoking and gender in acute coronary syndrome events. American Journal of Cardiology, 108, 1382-1386. doi:10.1016/j.amjcard.2011.06.059

[10] Jarvie, J., Wang, Y., Johnson, C. and Foody, J. (2011) Contemporary female smokers in the US are younger and of lower socioeconomic status. Health, 3, 357-361. doi:10.4236/health.2011.36060

[11] Korte, D., Schayck, O., Spiegel, P., et al. (2010) Supporting smoking cessation in healthcare: Obstacles in scientific understanding and tobacco addiction management. Health, 2, 1272-1279. doi:10.4236/health.2010.211189 